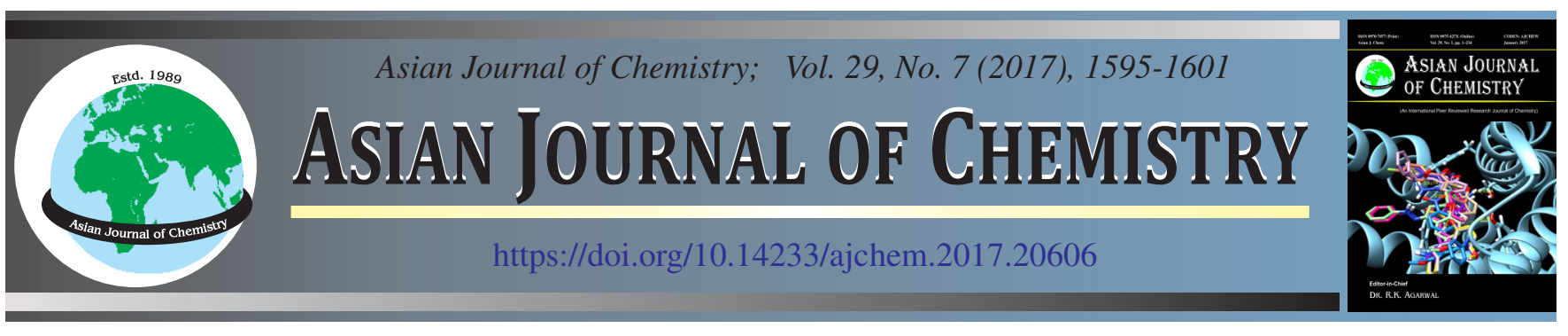

\title{
Determination of Cr(III) in Industrial Effluents by Zinc Oxide-Tin(IV) Antimonophosphate Nanocomposite Based Ion Selective Electrode
}

\author{
Sandeep Kaushal ${ }^{1}$, Mandeep Kaur $^{1}$, Susheel Kumar Mittal ${ }^{2}$ and Pritpal Singh ${ }^{1, *}$
}

\begin{abstract}
${ }^{1}$ Department of Chemistry, Sri Guru Granth Sahib World University, Fatehgarh Sahib-140 407, India
\end{abstract}
${ }^{2}$ School of Chemistry and Biochemistry, Thapar University, Patiala-147 004, India

*Corresponding author: Fax: +91 1763 234236; E-mail: dhillonps2003@gmail.com

\begin{abstract}
This investigation focuses on trace level determination of chromium(III) ions in industrial effluents by a novel zinc oxide-tin(IV) antimonophosphate nanocomposite based ion selective electrode. The distribution studies confirmed the high selectivity of the nanocomposite material for $\mathrm{Cr}$ (III) ions which was thus used as an electroactive material for fabrication of $\mathrm{Cr}$ (III) selective electrode. The material was characterized by FTIR, X-ray, SEM, TEM, EDX and TGA techniques. The membrane sensor exhibits a stable sub-Nernstian response to chromium(III) ions over a wide concentration range of $1 \times 10^{-7}$ to $1 \times 10^{-2} \mathrm{M}$ in the $\mathrm{pH}$ range $2.0-8.5$. The dynamic response time, limit of detection, life span and slope of the proposed sensor were $12 \mathrm{~s}, 1.0 \times 10^{-8} \mathrm{M}, 4 \mathrm{months}$ and $15 \mathrm{mV} / \mathrm{decade}$, respectively. The proposed sensor was successfully used for estimation of the activity of $\mathrm{Cr}$ (III) ions in electroplating and leather tannery effluents. The results obtained were validated by comparison with those obtained by UV-visible spectrophotometric and atomic absorption spectrometric techniques. The analytical utility of the proposed sensor was established by potentiometric titration of $\mathrm{Cr}(\mathrm{III})$ ions with EDTA solution.
\end{abstract}

Keywords: Nanocomposite, Tin(IV) antimonophosphate, Ion selective electrode, Ion exchanger, Membrane electrode.

\section{INTRODUCTION}

Water pollution by heavy metal ions discharged from various industries is a serious global concern. Due to their toxicity, bioavailability, accumulation and sedimentation in various environmental components, the heavy metals have adverse effect on micro-organisms, aquatic life and human beings. Process waste from mining operations, power generation, tanneries, electroplating, production of paints and pigments and electrical appliances may contain heavy metals at concentrations more than the permissible limits. The waste from these industries contains toxic heavy metal ions like mercury(II), cadmium(II), nickel(II), lead(II), copper(II) and chromium(III)/(VI). Chromium(III) has been known as vital micronutrient for humans and animals in diet, potentiating action of insulin, and carbohydrate and lipid metabolism [1]. Chromium(III) combines with vitamin $\mathrm{C}$ and $\mathrm{E}$ and is effective for minimizing oxidative stress and improvement of glucose metabolism in type-II diabetes mellitus patients [2]. The deficiency of chromium in diet may lead to problems in blood sugar metabolism, such as anxiety or fatigue, abnormal cholesterol metabolism and increased progress of atherosclerosis and slow healing after injury or surgery. Chromium(III) is available in wide range of foods including coffee nuts, green beans, broccoli, egg yolk, whole grain products and some brands of beer and wine [3].

According to U.S. National Academy of Science, the estimated safe and adequate daily dietary intake of chromium recommended in adults is 50-200 $\mu \mathrm{g}$ /day [4]. However, when intake of chromium is more than the permissible limit, it enters the food chain and leads to immense health hazards [5]. The exposure to high levels of chromium may cause skin irritation, dizziness, nausea, cancer, vomiting, diarrhea, respiratory problems, mood changes, weakened immune system and impaired thinking in humans [6].

Chromium has received considerable attention owing to its extensive use in wood treatment, pigments and paints, electroplating, glass industries, leather tanning, catalysis, steel manufacturing and other industrial applications. Owing to its long term toxicity towards humans, a highly sensitive, selective and quick method for estimation of chromium(III) is necessitated.

Various sophisticated analytical techniques like flame atomic absorption spectrometry (FAAS) [7], inductively coupled plasma-atomic emission spectroscopy (ICP-AES) [8], high performance liquid chromatography (HPLC) [9], X-ray 
fluorescence (XRF) [10], graphite furnace atomic absorption spectrometry [11] and gas chromatography with flame photometric detection [12] are generally employed for the trace level estimation of chromium. However all these analytical techniques involve expensive instrumentation, tedious procedure for sample analysis and are also time consuming. To overcome these limitations, the ion exchanger based sensors appeared to be an appealing alternative as these offer various advantageous features like simple instrumentation, relatively mild operating conditions, online monitoring, wide concentration range, low detection limit, a high efficiency of sorption from gaseous and liquid media.

In this manuscript, we report a novel zinc oxide-tin(IV) antimonophosphate nanocomposite, which was observed to be highly selective for $\mathrm{Cr}(\mathrm{III})$, with detection limit as low as $1.0 \times 10^{-8} \mathrm{M}$. The potency of present work has been established by quantitative estimation of $\mathrm{Cr}$ (III) ions in electroplating and leather tannery effluents. The novelty of work is reflected by the fact that no such membrane has been reported previously for estimation of $\mathrm{Cr}$ (III) ions in environmental waste samples.

\section{EXPERIMENTAL}

Analytical grade tin(IV) chloride, potassium pyroantimonate, phosphoric acid, hydrofluoric acid and hydrochloric acid have been used for synthesis without further purification. All the reagents were prepared in double distilled water. Thermal analysis was performed by heating nanocomposite material up to $700{ }^{\circ} \mathrm{C}$ at a constant increment of $10^{\circ} \mathrm{C} / \mathrm{min}$ in nitrogen atmosphere, using Hitachi SGA7400 thermogravimetric analyzer. IR spectra were recorded on a Perkin Elmer RXI FTIR spectrometer. X-ray diffraction patterns were obtained using PAN analytical system DY 3190 X-ray diffractometer. The spectrum was recorded between $5^{\circ}$ to $40^{\circ}$ at $2 \theta$, using $\mathrm{CuK}_{\alpha}$ radiation. The topography and elemental composition of the synthesized particles were recorded using JEOL scanning electron microscope and JSM 6510LV energy dispersive X-ray detector. Transmission electron microscopy (TEM) studies were carried out on model MIC JEM 2100. Potentiometric studies were done on Systronic digital potentiometer (model 318). Elico pH meter (model 1012) was employed to perform $\mathrm{pH}$ studies. Membrane thickness was measured using screw gauge.

Synthesis of zinc oxide-tin(IV) antimonophosphate (ZnO-SnSbP) nanocomposite: The zinc oxide-tin(IV) antimonophosphate (ZnO-SnSbP) nanocomposite ion exchanger was synthesized by sol-gel method. Tin(IV) chloride solution $(0.1 \mathrm{M})$ was added to a continuously stirred mixture of potassium pyroantimonate $(0.1 \mathrm{M})$ and phosphoric acid solutions $(0.1 \mathrm{M})$ at $60{ }^{\circ} \mathrm{C}$, in the volume ratio $2: 1: 1$. After complete addition, the mixture was stirred for $2 \mathrm{~h}$ and a gel of tin(IV) antimonophosphate (SnSbP) was obtained. Zinc oxide nanoparticles were then added to tin(IV) antimonophosphate gel. The resultant mixture was stirred for $6 \mathrm{~h}$ on a magnetic stirrer and then digested for $24 \mathrm{~h}$ with intermittent shaking. The precipitates were filtered and washed with double distilled water several times to remove the impurities. The precipitates of $\mathrm{ZnO}-\mathrm{SnSbP}$ obtained were dried at $40{ }^{\circ} \mathrm{C}$ in a hot air oven. The dried precipitates were converted into $\mathrm{H}^{+}$form by placing in $0.1 \mathrm{M} \mathrm{HCl}$ solution for $24 \mathrm{~h}$ with occasional shaking. The precipitates of $\mathrm{ZnO}-\mathrm{SnSbP}$ were filtered and washed with distilled water to remove excess of acid.

Ion exchange capacity: The ion exchange capacity of the sample was determined before proceeding for further electrochemical studies. Ion-exchange capacity was determined by column operation using sodium nitrate solution as an eluent. The $\mathrm{H}^{+}$ions eluted from the column were determined titrimetrically against standard solution of sodium hydroxide.

Distribution studies $\left(\mathbf{K}_{\mathbf{d}}\right)$ : The distribution studies were carried out to determine the distribution coefficients of different metal ions on the composite ion exchanger in aqueous medium. In typical procedure, $200 \mathrm{mg}$ of $\mathrm{ZnO}-\mathrm{SnSbP}$ nanocomposite in $\mathrm{H}^{+}$form was equilibrated separately with $20 \mathrm{~mL}$ of $0.01 \mathrm{M}$ solution of each of the metal ions for $24 \mathrm{~h}$ at room temperature with occasional shaking. The concentration of metal ions in solution, before and after equilibrium, was determined by standard EDTA solution [13]. The distribution coefficients $\left(\mathrm{K}_{\mathrm{d}}\right)$ of different metal ions were calculated using the formula:

$$
\mathrm{K}_{\mathrm{d}}=\frac{\mathrm{I}-\mathrm{F}}{\mathrm{F}} \times \frac{\mathrm{V}}{\mathrm{M}} \mathrm{mL} / \mathrm{g}
$$

where, I and $\mathrm{F}$ are the initial and final concentrations of metal ion in solution, respectively.

Fabrication of membrane: The ion exchange membranes of different thickness were prepared using $\mathrm{ZnO}$-SnSbP nanocomposite with epoxy resin as binder. The cation exchanger in finely powdered form (approximately $200 \mu \mathrm{M}$ ) was mixed thoroughly with araldite till a homogeneous slurry was obtained. The slurry was spread between the folds of a glossy paper. A pressure of $2.0 \mathrm{Kg} / \mathrm{cm}^{2}$ was applied for $24 \mathrm{~h}$ over the glass plates containing the glossy paper. The glossy paper was removed by dipping the membrane in distilled water. Circular membranes of different thickness were obtained by cutting with sharp knife.

Physiological characterization of membrane: The parameters such as thickness, water content, porosity and ion exchange capacity of the prepared membranes have been determined before further investigations.

Thickness: The thickness of the membrane was measured by a screw gauge. The difference between the average thickness of the membrane equilibrated with $1 \mathrm{M} \mathrm{NaCl}$ for $24 \mathrm{~h}$ and the dry membrane is a measure of swelling.

Water content: Water content was measured as the mass difference between the dried and wet swollen membranes. The wet membrane was weighed and then dried in oven until constant weight was attained. The water content was calculated by the following equation:

$$
\text { Water content }(\%)=\frac{\mathrm{W}_{\text {wet }}-\mathrm{W}_{\mathrm{dry}}}{\mathrm{W}_{\mathrm{dry}}} \times 100
$$

where $\mathrm{W}_{\text {wet }}$ and $\mathrm{W}_{\text {dry }}$ are the mass ( $\mathrm{g}$ ) of wet and dry membrane, respectively.

Porosity $(\boldsymbol{\varepsilon})$ : Porosity is regarded as the volume of water incorporated in the cavities per unit membrane volume and is calculated by the following relation:

$$
\varepsilon=\frac{m_{w}-m_{d}}{A L \rho_{w}}
$$


where $\mathrm{m}_{\mathrm{w}}$ and $\mathrm{m}_{\mathrm{d}}$ are the mass $(\mathrm{g})$ of wet and dry membrane, respectively, $\mathrm{L}$ is the thickness of the membrane, $\mathrm{A}$ is the area of the membrane and $\rho_{w}$ is the density of water.

Potential measurements: All measurements were carried out at $300 \pm 1 \mathrm{~K}$ with the following cell assembly:

$\mathrm{Hg}-\mathrm{Hg}_{2} \mathrm{Cl}_{2}, \mathrm{KCl}$ (sat.) | $0.05 \mathrm{M} \mathrm{Cr}$ (III) ॥

membrane II test solution I $\mathrm{KCl}$ (sat.), $\mathrm{Hg}_{2} \mathrm{Cl}_{2}-\mathrm{Hg}$

Chromium(III) solutions of concentration range $5 \times 10^{-9}$ to $5 \times 10^{-1} \mathrm{M}$ were used to study the performance of electrode. The electrode was stored in $5 \times 10^{-2} \mathrm{M}$ chromium(III) chloride solution after the experiment.

Analysis of environmental samples: Waste samples were collected from leather tanning unit, Jalandhar (Punjab), India and electroplating effluent samples were collected from electroplating unit at Ludhiana (Punjab), India. The collected samples were digested by UV-digester in the presence of suitable volumes of both concentrated $\mathrm{HNO}_{3}$ and $\mathrm{H}_{2} \mathrm{O}_{2}(30 \%)$ for $1 \mathrm{~h}$. The obtained solution was neutralized by $\mathrm{NaOH}$ ( $5 \mathrm{~mol}$ $\mathrm{L}^{-1}$ ) and $10 \mathrm{~mL}$ of this solution was treated under the conditions of recommended procedure [14]. The prepared samples were subjected to $\mathrm{Cr}$ (III) determination by AAS, spectrophotometric and proposed method.

\section{RESULTS AND DISCUSSION}

Morphological characterization: FTIR spectroscopic studies were carried out on pure tin(IV) antimonophosphate and zinc oxide-tin(IV) antimonophosphate nanocomposite (Fig. 1). The presence of sharp and broad band in the region $\approx$ $3450 \mathrm{~cm}^{-1}$ is attributed to interstitial water molecules [15]. The band at $1631 \mathrm{~cm}^{-1}$ is attributed to $\mathrm{H}-\mathrm{O}-\mathrm{H}$ bending and signifies the strong bonding of $\mathrm{OH}$ groups in the matrix [16]. The bands at $\approx 1062 \mathrm{~cm}^{-1}$ and $550 \mathrm{~cm}^{-1}$ are due to $\mathrm{P}-\mathrm{O}$ stretching and bending vibrations. The bands in the vicinity of $600-500 \mathrm{~cm}^{-1}$ are due to $\mathrm{Zn}-\mathrm{O}$ stretching in $\mathrm{ZnO}$ [17]. Peak at $636 \mathrm{~cm}^{-1}$ may be assigned to $\mathrm{M}-\mathrm{O}$ stretching.

FESEM analysis was carried out for the morphological study of $\mathrm{SnSbP}$ and $\mathrm{ZnO}-\mathrm{SnSbP}$ nanocomposite. The high resolution FESEM micrographs of SnSbP cation exchanger (Fig. 2a) reveal that the particles are aggregated as well as agglomerated. Fig. 2(b) shows distorted spherical shape of the $\mathrm{ZnO}-\mathrm{SnSbP}$ nanocomposite particles. EDX is used to find the

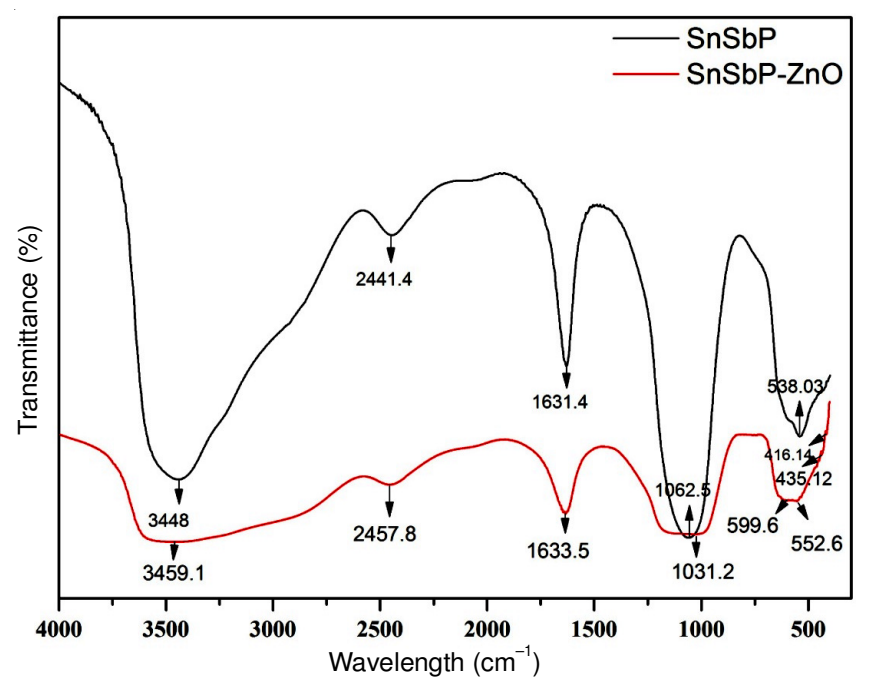

Fig. 1. FTIR spectra of SnSbP and $\mathrm{ZnO}-\mathrm{SnSbP}$ nanocomposite

elemental composition of SnSbP. The EDX spectrum of SnSbP (Fig. 2c) confirms the presence of $\mathrm{Sn}, \mathrm{Sb}, \mathrm{P}$ and $\mathrm{O}$ in the exchanger. Fig. 2(d) confirms the presence of $\mathrm{Sn}, \mathrm{Sb}, \mathrm{P}, \mathrm{O}$ and $\mathrm{Zn}$ in the nanocomposite.

The transmission electron micrographs of $\mathrm{ZnO}-\mathrm{SnSbP}$ (Fig. 3) reveal that the average particles size ranged between 22.6 and $27.0 \mathrm{~nm}$. Thus, the size of nanocomposite particles is in nano range.
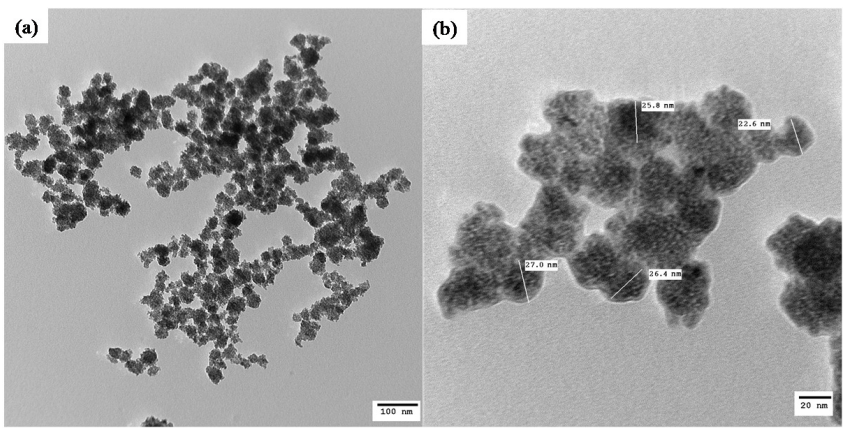

Fig. 3. TEM images of $\mathrm{ZnO}-\mathrm{SnSbP}$ nanocomposite at different magnifications

It is observed from the X-ray diffraction (XRD) patterns of synthesized SnSbP and ZnO-SnSbP nanocomposite (Fig.

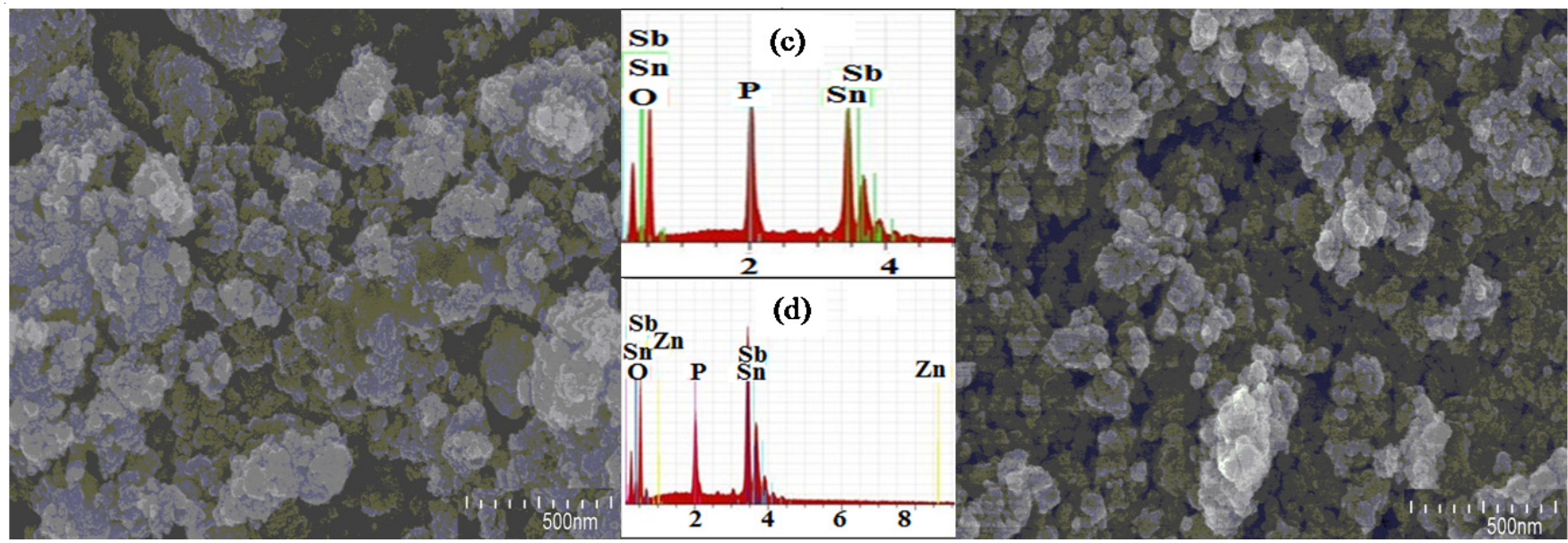

Fig. 2. FESEM images of (a) SnSbP (b) ZnO-SnSbP nanocomposite and EDS spectra of (c) SnSbP (d) ZnO-SnSbP nanocomposite 
4) that $\mathrm{SnSbP}$ is amorphous in nature, but the matrix assumes crystalline nature with the addition of $\mathrm{ZnO}$ nanoparticles. The thermogravimetric analysis of $\mathrm{ZnO}-\mathrm{SnSbP}$ nanocomposite (Fig. 5) was performed by heating the nanocomposite from room temperature to $1000^{\circ} \mathrm{C}$, with an increment of $10^{\circ} \mathrm{C} / \mathrm{min}$ in air. The $10.01 \%$ weight loss in the temperature range 60$125^{\circ} \mathrm{C}$ may be due to evaporation of water molecules from the sample [18]. Similarly, $5.96 \%$ weight loss in $210-310^{\circ} \mathrm{C}$ temperature range may be due to conversion of some phosphate into pyrophosphate [15]. The weight loss of $2.92 \%$ in the temperature range $390-460{ }^{\circ} \mathrm{C}$ may be attributed to condensation of exchangeable hydroxyl groups which is usual behaviour of inorganic ion exchangers [19].

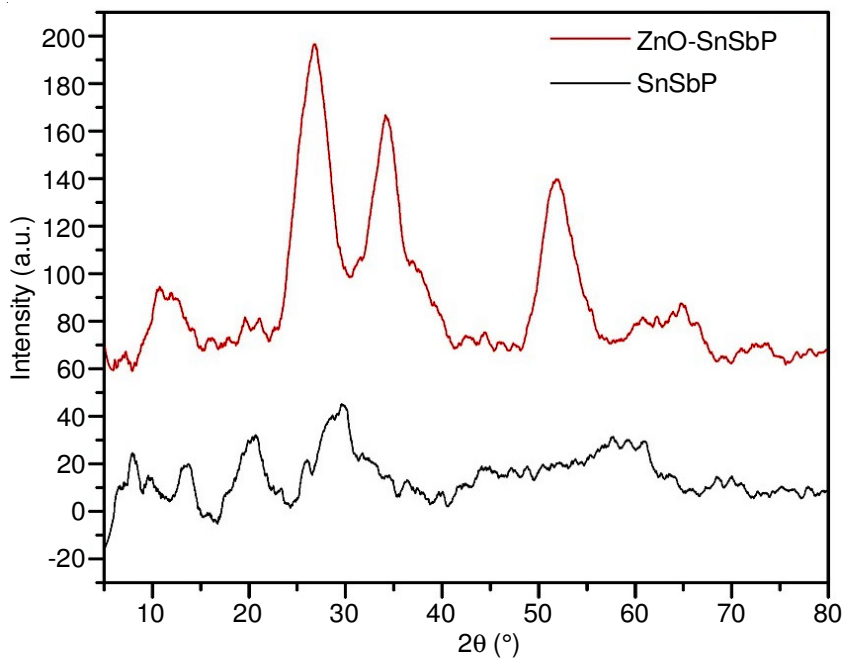

Fig. 4. XRD patterns of SnSbP and ZnO-SnSbP nanocomposite

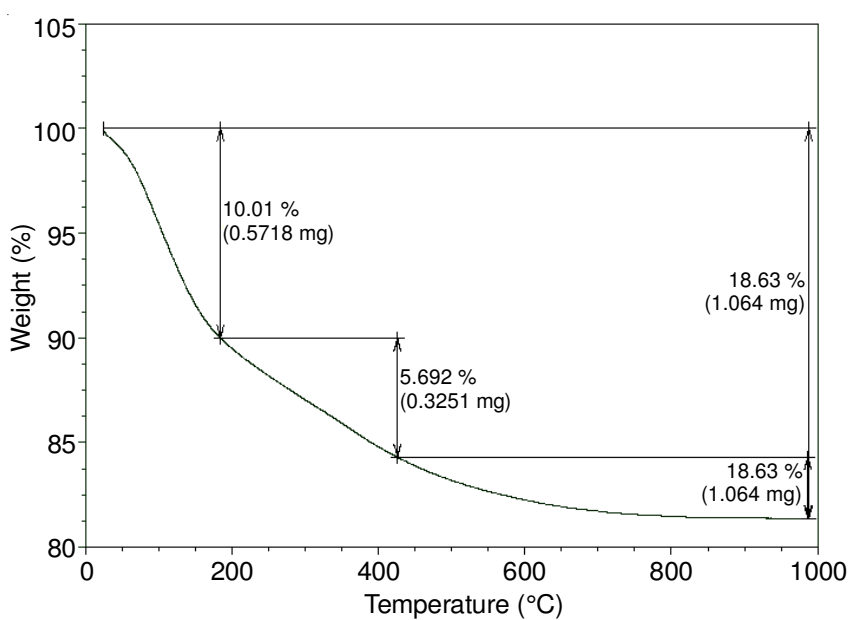

Fig. 5. TGA curve of ZnO-SnSbP nanocomposite

Distribution studies: The distribution coefficients calculated for various metal ions were found to be in the order: $\mathrm{Cr}$ (III) $575>\mathrm{Li}$ (I) $342>\mathrm{Ba}$ (II) $226>\mathrm{Na}$ (I) $107>\mathrm{Co}$ (II) $87>\mathrm{Cd}$ (II) $85>\mathrm{Mn}$ (II) $86>\mathrm{Ni}$ (II) $78>\mathrm{Ca}$ (II) $60>\mathrm{Mg}$ (II) $51>\mathrm{Pb}$ (II) $37>\mathrm{K}$ (I) $33>\mathrm{Hg}$ (II) $23>\mathrm{Zn}$ (II) $22>\mathrm{Fe}$ (III) $17>\mathrm{Cu}$ (II) 8 . The composite was found to be selective for $\mathrm{Cr}$ (III) metal ions. Hence, the synthesized nanocomposite ion exchanger was employed for the fabrication of $\mathrm{Cr}$ (III) selective electrode.

Usually, the ideal membrane should possess high ion exchange capacity, moderate porosity, water content, swelling and less thickness [20]. So, before employing the membrane as an ion selective electrode, properties like ion exchange capacity, thickness, water content, swelling and porosity of the membranes were determined (Table-1). The ZnO$\mathrm{Sn}$ (IV)SbP nanocomposite membrane (M-2) with moderate thickness, swelling, porosity, water content and better ion exchange capacity was selected for further studies.

\begin{tabular}{ccccc}
\multicolumn{5}{c}{ TABLE-1 } \\
PHYSIO-CHEMICAL CHARACTERISTICS OF \\
ZnO-Sn(IV)SbP CATION EXCHANGE MEMBRANE
\end{tabular}

Response time and life span of membrane electrode: The response time is the key factor in characterizing fabricated ion selective electrode. The measured electrode potential versus time plot is given in Fig. 6. As per IUPAC recommendations, the response time of the proposed electrode was observed to be $12 \mathrm{~s}$. The working period of this ion selective electrode was four months and it worked without any change in response time and detection limit. After this period, the electrode response does not remain reproducible and stable and the slope of the calibration curve decreases sharply.

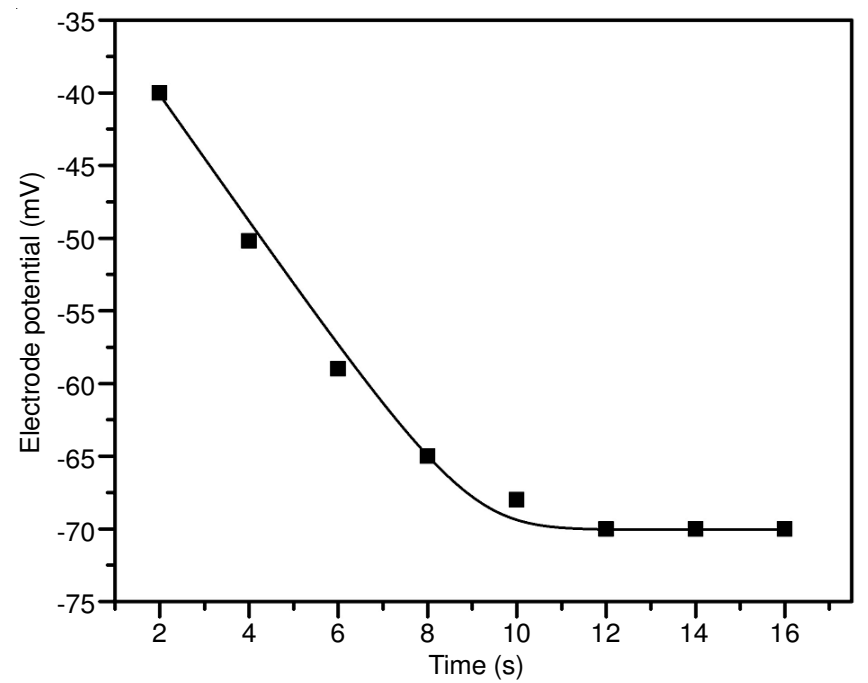

Fig. 6. Response time of $\mathrm{ZnO}-\mathrm{SnSbP}$ nanocomposite based ion selective electrode

Slope and detection limit: The detection limit of the proposed electrode was assessed in accordance with IUPAC recommendations [21]. Electrode potential values were plotted against log of activities of $\mathrm{Cr}$ (III) ions (Fig. 7). The calibration curve of the proposed membrane electrode indicated a sub Nernstian response of $15 \mathrm{mV} /$ decade over a wide concentration range of $1 \times 10^{-7}$ to $1 \times 10^{-2} \mathrm{M}$. The detection limit of $\mathrm{Cr}$ (III) ion selective electrode was evaluated from the cross section of two extrapolated lines to the base line potential and was found to be $1.0 \times 10^{-8} \mathrm{M}$. The reproduction of results is crucial for successful operation of an electrode. Thus, the experiments 


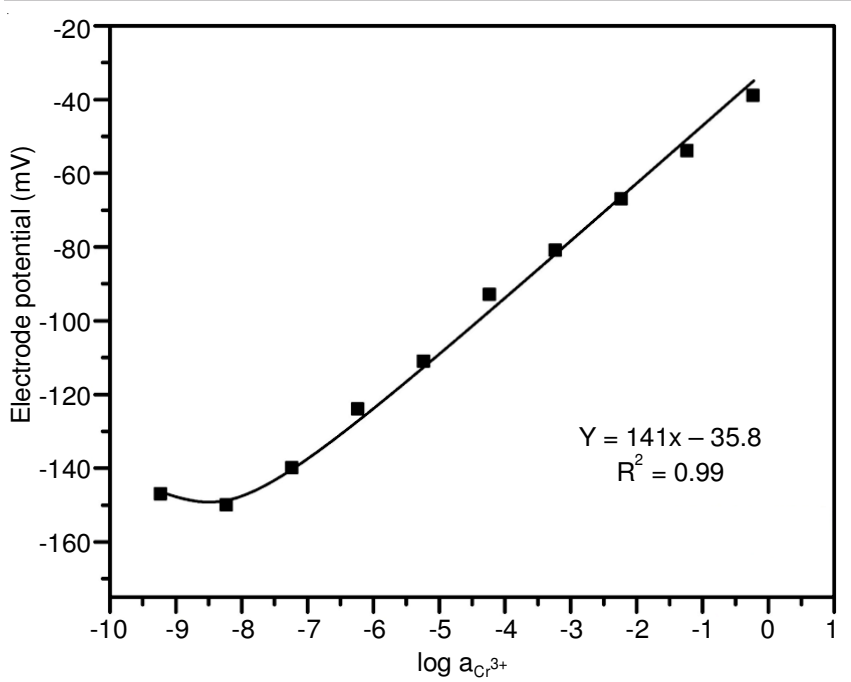

Fig. 7. Calibration curve of proposed $\mathrm{ZnO}-\mathrm{SnSbP}$ based $\mathrm{Cr}(\mathrm{III})$ selective electrode

were repeated five times to check and confirm the reproducibility of this electrode system. The standard deviation in the slope of calibration curve for the five measurements was observed to be $0.12 \mathrm{mV} /$ decade.

Effect of change in internal solution concentration: As observed from Fig. 8, a change in internal solution concentration does not have any significant effect on the response of proposed electrode, as reported by Ganjali et al. [22]. However, a small change in the intercept of the curve was observed.

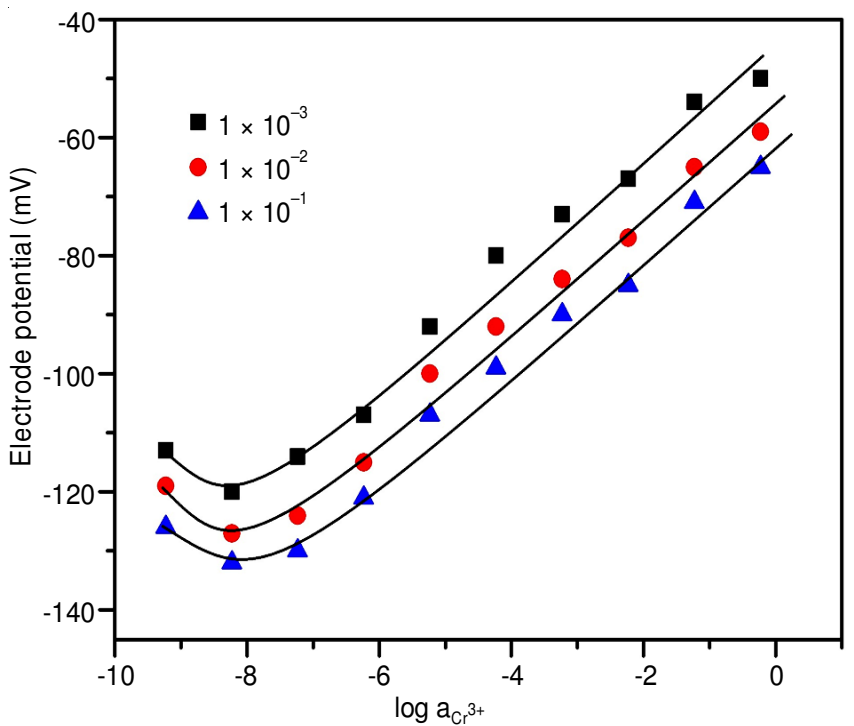

Fig. 8. Calibration curves of $\mathrm{ZnO}-\mathrm{SnSbP}$ membrane electrode using different concentrations of internal solution

Effect of non-aqueous solvents: The performance of proposed sensor was also studied in partially non-aqueous media (Table-2). It is clear from the slope of calibration curve that the proposed membrane electrode can be safely used in solutions with non-aqueous content up to $20 \%(\mathrm{v} / \mathrm{v})$. The working concentration range and slope of the electrode reduce sharply if the concentration of non-aqueous solvent exceeds this concentration range.
TABLE-2

EFFECT OF PARTIALLY NON AQUEOUS MEDIA ON SLOPE AND WORKING RANGE OF Cr(III) SELECTIVE ELECTRODE

\begin{tabular}{cccc}
\hline $\begin{array}{c}\text { Non-aqueous } \\
\text { Solvent }\end{array}$ & $\begin{array}{c}\text { Volume of } \\
\text { solvent } \\
\text { (v/v \%) }\end{array}$ & $\begin{array}{c}\text { Slope } \\
\text { (mV/decade) }\end{array}$ & $\begin{array}{c}\text { Measuring range } \\
\text { (M) }\end{array}$ \\
\hline \multirow{3}{*}{ Acetone } & 5 & 14.6 & $1 \times 10^{-7}$ to $1 \times 10^{-1}$ \\
& 10 & 14.4 & $1 \times 10^{-7}$ to $1 \times 10^{-1}$ \\
& 15 & 14.3 & $1 \times 10^{-7}$ to $1 \times 10^{-1}$ \\
& 20 & 14.1 & $1 \times 10^{-7}$ to $1 \times 10^{-1}$ \\
\hline Ethanol & 5 & 14.8 & $1 \times 10^{-7}$ to $1 \times 10^{-1}$ \\
& 10 & 14.6 & $1 \times 10^{-7}$ to $1 \times 10^{-1}$ \\
& 15 & 14.5 & $1 \times 10^{-7}$ to $1 \times 10^{-1}$ \\
& 20 & 14.3 & $1 \times 10^{-7}$ to $1 \times 10^{-1}$ \\
\hline
\end{tabular}

Effect of change in $\mathbf{p H}$ : The $\mathrm{pH}$ dependence of the membrane electrode was tested over the $\mathrm{pH}$ range 1.0 to 12.0 (Fig. 9). The $\mathrm{pH}$ was adjusted by addition of small drops of $\mathrm{NaOH}(0.1 \mathrm{M})$ or $\mathrm{HCl}(0.1 \mathrm{M})$ solution. It is noticed that the potential remains fairly constant in the $\mathrm{pH}$ range 3.0-8.5. At $\mathrm{pH}$ values lower than 2.0 , a potential decrease was observed. This decrease may be caused by the membrane response to the hydronium ions along with $\mathrm{Cr}$ (III) ions. On the other hand, the observed drift at higher $\mathrm{pH}$ values could be attributed to the formation of chromium(III) hydroxide.

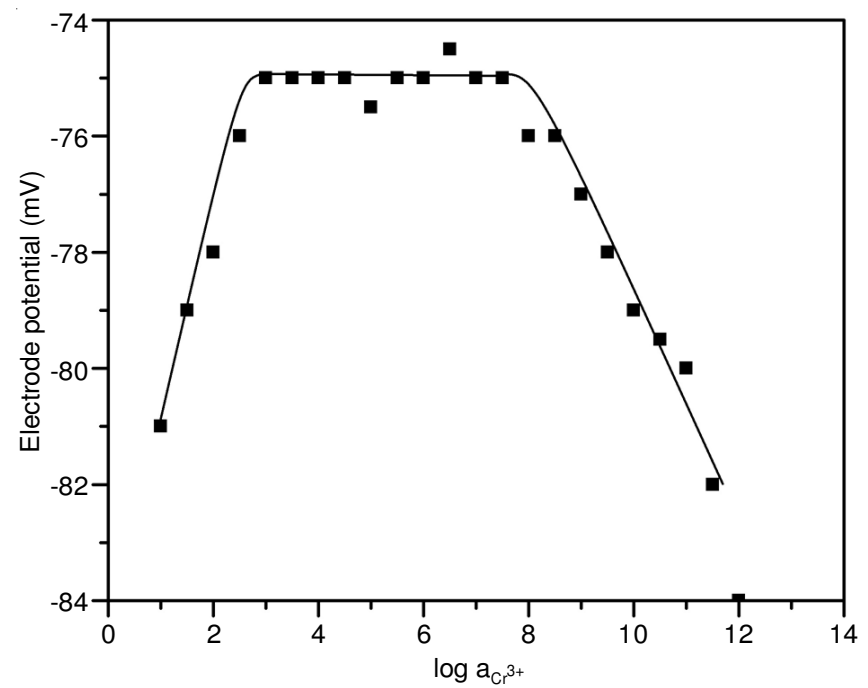

Fig. 9. Electrode potential response of $\mathrm{ZnO}-\mathrm{SnSbP}$ electrode in solutions of different $\mathrm{pH}$ values

Selectivity coefficients: The selectivity coefficients are the most essential characteristic of an ion selective electrode, which reflect relative response of the membrane sensor towards the primary ions over other ions present in solution. The selectivity coefficients of the membrane electrode were calculated by measuring its potential response in the presence of various interfering foreign cations by fixed interference method (FIM) [23]. Potentiometric selectivity coefficient $\left(\mathrm{K}_{\mathrm{a}, \mathrm{b}}^{\mathrm{Pot}}\right)$ describes the preference of the membrane electrode for $\mathrm{Cr}^{3+}$ ion relative to an interfering ion $\mathrm{B}$. Selectivity coefficients were determined from the potential measurements in solutions containing fixed concentration of interfering ion $\left(1 \times 10^{-3} \mathrm{M}\right)$ and varying concentrations of chromium(III) ions. The values of selectivity coefficients so determined are compiled in Table3. The selectivity coefficient values were observed to be in the 
TABLE-3

SELECTIVITY COEFFICIENTS $\left(\mathrm{K}_{\mathrm{a}, \mathrm{B}}^{\mathrm{Pot}}\right)$ OF THE PROPOSED ELECTRODE FOR DIFFERENT INTERFERING IONS

\begin{tabular}{cccc}
\hline $\begin{array}{c}\text { Interfering } \\
\text { ion }(\mathrm{B})\end{array}$ & $\mathrm{K}_{\mathrm{a}, \mathrm{B}}^{\mathrm{Pot}}$ & $\begin{array}{c}\text { Interfering } \\
\text { ion }(\mathrm{B})\end{array}$ & $\mathrm{K}_{\mathrm{a}, \mathrm{B}}^{\text {Pot }}$ \\
\hline $\mathrm{Li}^{+}$ & $0.50 \times 10^{-1}$ & $\mathrm{Mn}^{2+}$ & $1.30 \times 10^{-2}$ \\
$\mathrm{Na}^{+}$ & $1.80 \times 10^{-2}$ & $\mathrm{Ni}^{2+}$ & $1.30 \times 10^{-2}$ \\
$\mathrm{~K}^{+}$ & $1.20 \times 10^{-1}$ & $\mathrm{~Pb}^{2+}$ & $1.80 \times 10^{-3}$ \\
$\mathrm{Mg}^{2+}$ & $1.15 \times 10^{-3}$ & $\mathrm{Cd}^{3+}$ & $0.52 \times 10^{-2}$ \\
$\mathrm{Ca}^{2+}$ & $1.10 \times 10^{-2}$ & $\mathrm{Fe}^{3+}$ & $0.40 \times 10^{-3}$ \\
$\mathrm{Al}^{3+}$ & $1.80 \times 10^{-3}$ & $\mathrm{Ba}^{2+}$ & $0.60 \times 10^{-2}$ \\
$\mathrm{Cu}^{2+}$ & $0.52 \times 10^{-2}$ & $\mathrm{Hg}^{2+}$ & $1.80 \times 10^{-3}$ \\
$\mathrm{Co}^{2+}$ & $1.60 \times 10^{-2}$ & $\mathrm{Zn}^{2+}$ & $1.32 \times 10^{-2}$ \\
\hline
\end{tabular}

order of $10^{-2}$ and $10^{-3}$ for divalent and trivalent metal ions (except monovalent ions) which indicate that these ions will cause negligible interference in the functioning of the proposed chromium(III) selective electrode. Hence, the proposed membrane electrode can be used for estimation of $\mathrm{Cr}^{3+}$ ions in the presence of various interfering ions.

Potentiometric titration: The membrane electrode was also employed as an indicator electrode in the potentiometric titration of $\mathrm{Cr}(\mathrm{III})$ solution against an EDTA solution as titrant. For this, $10 \mathrm{~mL}$ of $1.0 \times 10^{-3} \mathrm{M} \mathrm{Cr}$ (III) solution was taken in a $50.0 \mathrm{~mL}$ beaker and titrated against $1.0 \times 10^{-2} \mathrm{M}$ EDTA solution. As shown in Fig. 10, the addition of EDTA causes regular decrease in electrode potential due to formation of $\mathrm{Cr}$ (III)EDTA complex and decrease in free $\mathrm{Cr}$ (III) ions concentration.

Analytical application: The proposed membrane electrode was employed for quantitative estimation of the activity of $\mathrm{Cr}$ (III) in electroplating and leather tannery effluents. The results obtained were validated by comparison with those obtained by atomic absorption spectrometric (AAS) and spectrophotometric techniques (Table-4).

Comparative studies with earlier reported $\mathrm{Cr}$ (III) selective electrodes: The response characteristics of proposed ion selective electrode have been compared with some other earlier reported $\mathrm{Cr}$ (III) ion selective electrodes (Table-5). The proposed sensor exhibits comparable linear range $\left(1 \times 10^{-7}\right.$

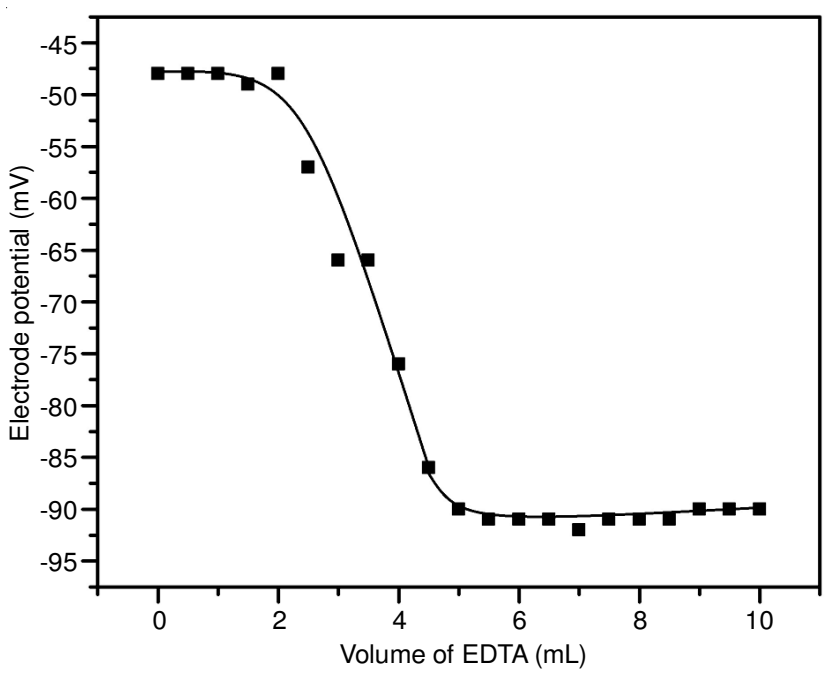

Fig. 10. Potentiometric titration of $\mathrm{Cr}(\mathrm{III})$ ions against EDTA solution with $\mathrm{ZnO}-\mathrm{SnSbP}$ membrane electrode

to $\left.1 \times 10^{-1} \mathrm{M}\right)$, lower detection limit $\left(1.0 \times 10^{-8} \mathrm{M}\right)$, better $\mathrm{pH}$ working range and response time, in comparison to other reported electrodes for estimation of $\mathrm{Cr}$ (III) ions.

\section{Conclusion}

In the present investigation, a membrane electrode has been prepared from zinc-oxide-tin(IV) antimonophosphate nanocomposite by using araldite as binder. Various characteristics of the membrane like porosity, water content, swelling etc. have been investigated. The electrode has been successfully used for estimation of low levels of $\mathrm{Cr}$ (III) in effluents from leather tanning and electroplating industries. The analytical results for estimation of $\mathrm{Cr}$ (III) obtained by the proposed electrode are nearly the same as obtained by other techniques like AAS and spectrophotometry. The proposed electrode can be used in the solutions with $\mathrm{pH} 3.0-8.5$ and also in partially non-aqueous media without any significant variation in its response. The proposed membrane electrode exhibits better linear range and low limit of detection as compared to earlier reported electrodes.

TABLE-4

COMPARISON OF ANALYTICAL RESULTS OF WATER SAMPLES USING PROPOSED MEMBRANE ELECTRODE WITH THOSE OBTAINED BY AAS AND SPECTROPHOTOMETRIC TECHNIQUES

\begin{tabular}{cccc}
\hline \multirow{2}{*}{ Sample description } & \multicolumn{3}{c}{ Concentration of Cr(III) ions in ppm as estimated by } \\
\cline { 2 - 4 } & AAS method (standard deviation) & Spectrophotometer (standard deviation) & Proposed method (standard deviation) \\
\hline Electroplating & $16.11( \pm 0.012)$ & $16.06( \pm 0.016)$ & $16.03( \pm 0.019)$ \\
Leather tanning & $34.12( \pm 0.010)$ & $33.78( \pm 0.015)$ & $33.85( \pm 0.021)$ \\
\hline
\end{tabular}

TABLE-5

COMPARISON OF RESPONSE CHARACTERISTICS OF PROPOSED ZnO-SnSbP

ELECTRODE AND OTHER REPORTED CHROMIUM SELECTIVE ELECTRODES

\begin{tabular}{|c|c|c|c|c|c|c|}
\hline Linear response $(\mathrm{M})$ & $\begin{array}{l}\text { Low detection } \\
\text { limit }(\mathrm{M})\end{array}$ & $\begin{array}{c}\text { Slope } \\
\text { (mV/decade) }\end{array}$ & $\begin{array}{l}\text { Slope in the presence } \\
\text { of non-aqueous solvent }\end{array}$ & $\mathrm{pH}$ range & $\begin{array}{l}\text { Response } \\
\text { time (s) }\end{array}$ & Ref. \\
\hline $3.16 \times 10^{-6}$ to $1.0 \times 10^{-1}$ & $1.58 \times 10^{-6}$ & $22.0 \pm 0.5$ & - & $3.0-7.0$ & 10 & [24] \\
\hline $2.0 \times 10^{-7}$ to $1.0 \times 10^{-1}$ & $9.0 \times 10^{-8}$ & $19.8 \pm 0.2$ & - & $2.2-5.0$ & $10-15$ & [25] \\
\hline $1.0 \times 10^{-6}$ to $1.0 \times 10^{-1}$ & $2.8 \times 10^{-7}$ & $19.9 \pm 0.2$ & - & $2.0-7.0$ & 9 & [26] \\
\hline $3.0 \times 10^{-6}$ to $1.0 \times 10^{-2}$ & $6.3 \times 10^{-7}$ & 19.8 & - & - & 20 & [27] \\
\hline $1.7 \times 10^{-6}$ to $1.0 \times 10^{-2}$ & - & 20 & - & - & 20 & [28] \\
\hline $8.3 \times 10^{-7}$ to $1.0 \times 10^{-1}$ & $6.3 \times 10^{-7}$ & - & - & $2.0-5.5$ & 22 & [29] \\
\hline $1.0 \times 10^{-7}$ to $1.0 \times 10^{-1}$ & $1.0 \times 10-8$ & 15 & - & $3.0-8.5$ & 12 & Present Work \\
\hline
\end{tabular}




\section{REFERENCES}

1. R.A. Anderson, N. Cheng, N.A. Bryden, M.M. Polansky, N. Cheng, J. Chi and J. Feng, Diabetes, 46, 1786 (1997); https://doi.org/10.2337/diab.46.11.1786.

2. J.L. Wang and D. Lai, J. Affect. Disord., 110, 191 (2008); https://doi.org/10.1016/j.jad.2008.01.005.

3. W.T. Cefalu and F.B. Hu, Diabetes Care, 27, 2741 (2004); https://doi.org/10.2337/diacare.27.11.2741.

4. D.E. Kimbrough, Y. Cohen, A.M. Winer, L. Creelman and C.A. Mabuni, Crit. Rev. Environ. Sci. Technol., 29, 1 (1999); https://doi.org/10.1080/10643389991259164.

5. V.K. Gupta, M. Gupta and S. Sharma, Water Res., 35, 1125 (2001); https://doi.org/10.1016/S0043-1354(00)00389-4.

6. S. Rengaraj, K.H. Yeon and S.H. Moon, J. Hazard. Mater., 87, 273 (2001); https://doi.org/10.1016/S0304-3894(01)00291-6.

7. N. Aristidis, G.A. Anthemidis, J.S. Zachariadis and J.A. Kougoulis, Talanta, 57, 15 (2002);

https://doi.org/10.1016/S0039-9140(01)00676-2.

8. A.J. Bednar, R.A. Kirgan and W.T. Jones, Anal. Chim. Acta, 632, 27 (2009); https://doi.org/10.1016/j.aca.2008.10.050.

9. J. Lintschinger, K. Kalcher, W. Gossler, G. Kolbl and M. Novic, Fresenius J. Anal. Chem., 351, 604 (1995); https://doi.org/10.1007/BF00323333.

10. P.R. Aranda, S. Moyano, L.D. Martinez and I.E. De Vito, Anal. Bioanal. Chem., 398, 1043 (2010); https://doi.org/10.1007/s00216-010-3950-y.

11. I.W.F. Davidson and W.L. Secrest, Anal. Chem., 44, 1808 (1972); https://doi.org/10.1021/ac60319a021.

12. T.-H. Ding, H.-H. Lin and C.-W. Whang, J. Chromatogr. A, 1062, 49 (2005);

https://doi.org/10.1016/j.chroma.2004.11.034.

13. C.N. Reilley, R.W. Schmid and F.S. Sadek, J. Chem. Educ., 36, 555 (1959); https://doi.org/10.1021/ed036p555.

14. A. Hamza, A.S. Bashammakh, A.A. Al-Sibaai, H.M. Al-Saidi and M.S. El-Shahawi, J. Hazard. Mater, 178, 287 (2010); https://doi.org/10.1016/j.jhazmat.2010.01.075.
15. S.A. Inamuddin, S. Khan, W. Siddiqui and A. Khan, Talanta, 71, 841 (2007); https://doi.org/10.1016/j.talanta.2006.05.042.

16. C.N.R. Rao, Chemical Application of Infrared Spectroscopy, Academic Press, New York, p. 353 (1963).

17. F. Parvizian, S.M. Hosseini, A.R. Hamidi, S.S. Madaeni and A.R. Moghadassi, J. Taiwan Inst. Chem. Eng., 45, 2878 (2014); https://doi.org/10.1016/j.jtice.2014.08.017.

18. C. Duval, Inorganic Thermogravimetric Analysis, Elsevier, Amsterdam, (1963).

19. K. Moosavi, S. Setayeshi, M.G. Maragheh, S. Javadahmad, M.R. Kardan and S. Nosrati, J. Appl. Sci. (Faisalabad), 9, 2180 (2009); https://doi.org/10.3923/jas.2009.2180.2184.

20. M.M.A. Khan and Rafiuddin, Desalination, 272, 306 (2011); https://doi.org/10.1016/j.desal.2011.01.041.

21. R.P. Buck and E. Lindner, Pure Appl. Chem., 66, 2527 (1994); https://doi.org/10.1351/pac199466122527.

22. M.R. Ganjali, M. Rezapour and S. Haghgoo, Sens. Actuator B Chem., 89, 21 (2003); https://doi.org/10.1016/S0925-4005(02)00422-7.

23. Y. Umezawa, K. Umezawa and H. Sato, Pure Appl. Chem., 67, 507 (1995); https://doi.org/10.1351/pac199567030507.

24. Lutfullah, M. Rashid, F. Khan and R. Wahab, Ind. Eng. Chem. Res., 53, 14897 (2014); https://doi.org/10.1021/ie501788a.

25. P. Kumar and H.K. Sharma, Electrochim. Acta, 87, 925 (2013); https://doi.org/10.1016/j.electacta.2012.09.027.

26. T.A. Ali, A.L. Saber, G.G. Mohamed and T.M. Bawazeer, Int. J. Electrochem. Sci., 9, 4932 (2014).

27. M.B. Gholivand and F. Sharifpour, Talanta, 60, 707 (2003); https://doi.org/10.1016/S0039-9140(03)00130-9.

28. A.K. Singh, A. Panwar, S. Kumar and S. Baniwal, Analyst, 124, 521 (1999); https://doi.org/10.1039/a901162e.

29. A.K. Singh, V.K. Gupta and B. Gupta, Anal. Chim. Acta, 585, 171 (2007); https://doi.org/10.1016/j.aca.2006.11.074.

30. R.K. Sharma and A. Goel, Anal. Chim. Acta, 534, 137 (2005); https://doi.org/10.1016/j.aca.2004.11.026. 